\title{
L'itinéraire atlantique de Juan Germán Roscio et la naissance du républicanisme hispanique
}

The Atlantic Itinerary of Juan German Roscio and the Birth of Hispanic

Republicanism

\section{Clément Thibaud}

\section{(2) OpenEdition}

\section{Journals}

\section{Édition électronique}

URL : https://journals.openedition.org/ahrf/12108

DOI : 10.4000/ahrf.12108

ISSN : 1952-403X

Éditeur :

Armand Colin, Société des études robespierristes

Édition imprimée

Date de publication : 1 septembre 2011

Pagination : 55-77

ISBN : 978-2-200-92700-4

ISSN : 0003-4436

\section{Référence électronique}

Clément Thibaud, «L'itinéraire atlantique de Juan Germán Roscio et la naissance du républicanisme hispanique », Annales historiques de la Révolution française [En ligne], 365 | Juillet-septembre 2011, mis en ligne le 01 septembre 2014, consulté le 22 avril 2022. URL : http://journals.openedition.org/ahrf/ 12108 ; DOI : https://doi.org/10.4000/ahrf.12108 


\title{
L'ITINÉRAIRE ATLANTIQUE DE JUAN GERMÁN ROSCIO ET LA NAISSANCE DU RÉPUBLICANISME HISPANIQUE
}

Clément THIBAUD

\begin{abstract}
Le Vénézuélien Juan Germán Roscio rédigea la première déclaration d'indépendance hispanique et contribua à l'une des premières constitutions de la région. Il fut également l'un des premiers penseurs du républicanisme moderne dans le monde hispano-américain. L'article tente d'expliquer, à travers ce parcours singulier, la précocité et la radicalité de la révolution d'indépendance vénézuélienne en la rapportant à la politisation des hiérarchies raciales et à la question religieuse.
\end{abstract}

Mots-clés : Amérique latine, indépendance, républicanisme, révolution, Venezuela.

La Terre-Ferme, si l'on y inclut le Venezuela et la Colombie actuelle, figure l'espace où les indépendances prirent le tour le plus radical de toute l'Amérique latine. C'est là que les premières émancipations explicites vis-à-vis de l'Espagne furent déclarées sur le modèle des États-Unis de Jefferson et de Franklin, dès $1811^{1}$. C'est là encore qu'est né le républicanisme moderne et qu'ont été promulguées les premières constitutions écrites du monde hispanique, quelques mois avant l'adoption à Cadix de la charte libérale espagnole. Les députés de la petite république andine de Tunja, au Nord de Bogotá, pouvaient ainsi écrire que :

«Tous les rois sont égaux aux autres hommes, et ils ont été placés sur le trône par la volonté des peuples afin de les maintenir en paix, d'admi-

(1) David Armitage, The Declaration of Independence. A Global History, Cambridge (Mass.), Londres, Harvard University Press, 2007, p. 199-208. 
nistrer la justice et de les rendre heureux. De sorte que s'ils ne respectent pas ce pacte sacré, ou si leur règne est incompatible avec la félicité des peuples, ou si le veut la volonté générale, ceux-ci ont le droit d'en élire un autre, ou de changer absolument la forme de son gouvernement en éteignant la monarchie $»^{2}$.

La radicalité du ton était exceptionnelle dans le contexte hispanique, d'autant plus que la province n'avait pas fait sécession avec l'Espagne. Partout ailleurs, sauf au Venezuela, la forme républicaine de gouvernement était taboue ${ }^{3}$. À l'échelle du sous-continent, il n'y avait que dans l'Uruguay d'Artigas qu'un projet de constitution confédérale, daté de 1813, mentionnait la « forme de gouvernement républicain $»^{4}$.

Le Vénézuélien Juan Germán Roscio fut l'un des principaux promoteurs de ce premier républicanisme. Il en fut même l'un des plus grands théoriciens latino-américains avec le Mexicain Servando Teresa de Mier ${ }^{5}$ et l'Équatorien Rocafuerte sur qui il eut une profonde influence $^{6}$. Député et membre de l'exécutif confédéral, Roscio fit paraître en 1811 un Patriotisme de Nirgua et abus des rois ${ }^{7}$. En 1817, il publia en exil à Philadelphie Le triomphe de la liberté sur le despotisme alors que la cause de l'indépendance paraissait perdue. Ce livre constitue sans doute le plus grand manifeste républicain des guerres d'indépendance hispaniques ${ }^{8}$. Bien sûr, l'évocation du parcours de Roscio ne permet pas de s'attaquer aux «causes » de l'indépendance en une sorte de téléologie rétrospective. Comme l'a montré François-Xavier Guerra, les

(2) Chap. I, art. 27 dans Manuel Antonio Pombo et José Joaquín Guerra (comp.), Constituciones de Colombia, Bogotá, Banco Popular, 1986, t. I, p. 478.

(3) Gabriel Di Meglio, «República - Argentina », Javier Fernández Sebastián (dir.), Diccionario Político y social del mundo iberoamericano, Madrid, Fundación Carolina, SECC/CEPC, 2009, p. 1273.

(4) Dans le Chili de O’Higgins, où la chose était pourtant en débat, le mot n'apparaît pas dans la constitution provisoire de 1818. Diana Veneros Ruzz-Tagle, «República-Chile », ibid., p. 1298. 2004 , p. 599

(5) Christopher Domínguez Michael, Vida de Fray Servando, México, Ediciones Eras,

(6) José Antonio Aguilar, «Vicente Rocafuerte y la invención de la república hispanoamericana 1821-1823 », José Antonio AgulLAR et Rafael RoJas (coord.), El republicanismo en Hispanoamérica, Mexico, Fondo de Cultura Económica, 2002, p. 351-387.

(7) Juan Germán Roscio, Patriotismo de Nirgua y abuso de los reyes, Caracas, Imprenta de Juan Baillío, 1811. Le texte, signé à Caracas le 18 septembre 1811, fut inséré dans El Observador Caraqueño, № $15,1811$.

(8) Id., El triunfo de la libertad sobre el despotismo en la confesión de un pecador arrepentido de sus errores politicos..., Philadelphie, En la imprenta de Thomas H. Palmer, 1817. Une édition plus accessible est celle de Caracas, Biblioteca Ayacucho, 1996, citée à la suite. 
indépendances ne furent pas une affaire de « précurseurs »; elles découlèrent de la crise monarchique ouverte en 1808 par l'invasion française 9 . Roscio lui-même confirme cette interprétation puisqu'il proclama à plusieurs reprises qu'il ne devint républicain qu'en $1809^{10}$. Son itinéraire éclaire plutôt les relations entre l'expérience sociopolitique d'un sujet de l'Empire et un destin révolutionnaire fasciné par la question républicaine. En d'autres termes, et pour reprendre les mots de Timothy Tackett : comment Roscio, ce notable respecté de Caracas, devint-il révolutionnaire ${ }^{11}$ ? Pourquoi ce dévot du « pouvoir tyrannique des monarchies chrétiennes ${ }^{12} »$, selon ses propres termes, finit-il par revêtir le bonnet phrygien? Ce thème en cache un autre d'une extrême importance dans la vie de Roscio : la question des hiérarchies racialisées, qui, à notre sens, sous-tend l'adhésion existentielle du Vénézuélien à un républicanisme militant.

\section{La politisation des généalogies}

La thèse est la suivante : le républicanisme antimonarchique de Roscio doit être rapporté à la politisation des frontières raciales à la fin de l'époque coloniale ${ }^{13}$. La société vénézuélienne se caractérisait alors par sa relative fluidité, liée à la négociation des statuts racialisés qui l'organisait. Le métissage y était plus poussé qu'ailleurs tandis que les esclaves y étaient peu nombreux - sauf dans certaines régions comme les vallées orientales de Caracas. La catégorie juridique de castas rassemblait l'ensemble des personnes libres n'appartenant ni à la république des Espagnols ni à celle des Indiens ${ }^{14}$. Ces métis étaient connus en Terre-Ferme sous le nom de Pardos ou Morenos. Ces Afrodescendants composaient presque la majorité de la population. On estimait

(9) François-Xavier GuErra, Modernidad e independencias, Madrid, Mapfre, 1992.

(10) Il l'avoua ainsi à la tribune du congrès d'Angostura le 17 décembre 1819 : « Ciegamente sacrifiqué mis servicios a la tiranía española hasta el año de 1809 », " Sesión extraordinaria del 17 de diciembre », Correo del Orinoco, 18.XII.1819. Il l'écrit également dans le Triomphe.

(11) Timothy Таскетт, Par la volonté du peuple. Comment les députés de 1789 sont devenus révolutionnaires, Paris, Albin Michel, 1997.

(12) Juan Germán Roscio, El triunfo..., op. cit., p. 10.

(13) On prend le parti de ne pas adopter l'usage politiquement correct des guillemets pour encadrer le terme de race, considéré ici comme un pur artefact sociopolitique.

(14) Le terme de république, dans le monde hispanique, était d'usage courant sous l'Ancien Régime. Il désignait communément une corporation comme c'est le cas ici, et, le plus souvent, une municipalité ou toute communauté ordonnée et régie obéissant au principe du bien commun. Le passage du républicanisme monarchique et corporatif à sa forme antimonarchique constitue l'un des enjeux essentiels de l'œuvre de Roscio. Cf. n. 71. 
qu'en 1810 le Venezuela comptait 22\% de Blancs, $23 \%$ d'Indiens, $48 \%$ de libres d'origine africaine et $7 \%$ d'esclaves pour une population totale de 900000 âmes $^{15}$. Ces Pardos formaient une population disparate, socialement clivée mais perçue, à juste titre, comme désireuse d'accéder aux privilèges réservés au corps de la république des Espagnols. Au $\mathrm{XVIII}^{\mathrm{e}}$ siècle, nombre d'entre eux, enrichis par le commerce ou l'artisanat, prirent conscience de leur dignité ${ }^{16}$. Cette dynamique appelait en retour la réaffirmation des hiérarchies de couleur de la part des élites sociales et des autorités. En résultait un effet de ciseau entre ouverture et fermeture qui plaçait certains métis dans une situation intenable. La mobilité sociale que leur ouvrait leur talent ou leur fortune rencontrait le préjugé et les discriminations légales liées à la notion de " pureté de sang ». Les humiliations obligeaient les libres de couleur à un retour réflexif sur eux-mêmes ${ }^{17}$ et sur les hiérarchies qui les minorisaient dans l'ordre colonial.

Roscio, en effet, était métis. Il naquit dans la région mêlée des Llanos, dans le village de San Francisco de Tiznados, le 27 mai 1763. Son père était originaire de Milan. Il avait servi l'armée espagnole en tant qu'officier et s'était installé dans les plaines où il possédait quelques terres. Sa mère, Paula María Nieves, était fille naturelle d'une mestiza ${ }^{18}$, c'est-à-dire quarteronne de sang indien ${ }^{19}$. Roscio était tenu pour quinteron d'Indien selon les classifications raffinées des $\operatorname{castas}^{20}$. Il provenait d'une famille sinon obscure, du moins modeste. Son apparence physique était sans doute celle d'un Blanc ${ }^{21}$. Il put entrer à l'Université en 1774 grâce à ses appuis au sein de l'aristocratie titrée de Caracas comme le comte

(15) José Manuel Restrepo, Historia de la Revolución de la República de Colombia en la América meridional, Besançon, Imprenta de José Jacquin, 1858, t. I, p. XIV.

(16) Frédérique LANGUE, « Les pardos vénézuéliens, hétérodoxes ou défenseurs de l’ordre social? », Nuevo Mundo Mundos Nuevos, Coloquios, 2009. http://nuevomundo.revues.org/56302, [en ligne], consulté le 22 décembre 2010.

(17) Ce n'est sans doute pas par hasard si le «tract» radical de Roscio en 1817 prend la forme d'une confession.

(18) Ángel Rafael Almarza Villalobos, « La limpieza de sangre en el Colegio de Abogados de Caracas a finales del siglo XVIII », Fronteras de la Historia, n 10, 2005, p. 305-328, ici p. 313.

(19) «Información de calidad del Dr. Juan Germán Roscio... », Caracas, 1798-1805, Archivo General de la Nación, Limpieza de Sangre, t. XXXIII, fol. 273-456 reproduit partiellement dans Santos Rodulfo CoRTés, El regimen de «las gracias al sacar » en Venezuela durante el período hispánico, Caracas, Academia Nacional de la Historia, 1978, t. II, p. 128-155 et intégralement par Hector PARra MÁrQuez, Historia del colegio de abogados de Caracas, Caracas, Imprenta Nacional, 1952, t. I, p. 429-471.

(20) Ibid., t. I, p. 344. Quinterón en espagnol.

(21) Ibid. 
de San Javier ${ }^{22}$. Brillant élève, il devint docteur en droit canon (1794) puis civil (1800) et professeur de l'Université en tant que « régent perpétuel » de la chaire d'Instituta à partir de $1798^{23}$. L'Académie royale de droit public espagnol le nomma juge séculier la même année et c'est tout naturellement qu'il souhaita s'inscrire au barreau. Pour ce faire, il devait solliciter son intégration au collège royal des avocats de Caracas ${ }^{24}$. C'est là que ses ennuis commencèrent. Sur la base de l'impureté de son sang, la corporation lui refusa son admission au barreau de 1798 à 1805. Les statuts de la compagnie rejetaient tout impétrant dont le sang colporterait la macule de l'hérésie, du paganisme ou de toute « mauvaise race » :

«Qu'ainsi les candidats comme leurs parents, et grands-parents paternels, et maternels, aient été vieux chrétiens, purs de toute mauvaise race de noir, mulâtre, ou de toute autre pareille, et sans tache aucune de Maure, Juif, ou nouvellement convertis à notre Sainte Foi Catholique, ni autre qui soit infâme $»^{25}$.

Anticipant l'objection, Roscio avait présenté sa requête en invoquant la récente cédule dite de Gracias al sacar ${ }^{26}$. Celle-ci permettait aux castas d'obtenir auprès des autorités monarchiques des « dispenses de qualité » contre monnaie sonnante et trébuchante. Il fit également remarquer que l'impureté de sang ne concernait pas les Indiens. Stratégie mal à propos car les élites vénézuéliennes avaient rejeté la loi estimant qu'elle aboutirait à la subversion de tout l'édifice social ${ }^{27}$. Le rejet de la candidature de Roscio s'inscrivait aussi dans un mouvement plus général. La Couronne avait en effet créé aux Indes des collèges d'avocats et des acadé-

(22) Josep-Ignaci SARAnyana (dir.), Teología en América Latina, vol. II-2. De las guerras de independencia hasta finales del siglo XIX (1810-1899), Francfort, Iberoamericana-Vervuert, 2005, p. 258.

(23) Nydia Ruz, Las confesiones de un pecador arrepentido. Juan Germán Roscio y los orígenes del discurso liberal en Venezuela, Caracas, Tropykos, 1996, p. 27-28.

(24) Hector Parra Márquez, Historia del colegio de abogados de Caracas, Caracas, Imprenta Nacional, 1952. C'était le nom officiel de la corporation rassemblant tous les avocats de la capitainerie.

(25) Statuts du Real Colegio de Abogados de Caracas reproduits dans Hector PARra Márquez, op. cit., p. 178. Ici le titre XIII.

(26) La cédule date du 10 février 1795. «Invocación de las Gracias al Sacar hecha por Juan Germán Roscio... » dans Santos Rodulfo CoRTés, op. cit., t. I, p. 343-348. «Representación de Don Juan Germán Roscio a los Señores Decano y oficiales del ilustre Colegio de abogados de Caracas... ", Caracas, 11 novembre 1798, dans Hector Parra Márquez, op. cit., p. 144.

(27) Ayuntamiento de la Ciudad de Caracas, «Acta », 28 novembre 1796, dans Lila MAgO de Chópite et José Hernández Palomo (éd.), El Cabildo de Caracas (1750-1821), Séville, CSIC, 2002, p. 373. 
mies d'apprentissage juridique après la guerre de Sept ans pour diffuser la connaissance du droit positif espagnol (derecho patrio) au détriment des droits romain et canon. Cette conception éclairée s'accompagnait d'une fermeture accrue de ces professions aux enfants naturels et aux libres de couleur ${ }^{28}$. Le contexte explique également le refus obstiné du collège royal. La capitainerie vivait dans la crainte des désordres liés à la révolte de Saint-Domingue ${ }^{29}$. Quelque mois avant que Roscio ne demande son intégration au barreau, une conspiration républicaine avait plongé les autorités dans la panique. Ses chefs étaient les Créoles Manuel Gual et José María España. Ils s'étaient alliés aux Espagnols ${ }^{30}$ exilés à la Guaira à la suite de la conjuration madrilène de San Blas, le 3 février 1796. Avec une cinquantaine d'Américains de toutes qualités et conditions, dont beaucoup de pardos libres et cinq esclaves ${ }^{31}$, ils organisèrent un mouvement séditieux visant à abattre le gouvernement au nom des Droits de l'Homme et du républicanisme classique. Les chefs de la conjuration firent publier, sans doute à la Guadeloupe ${ }^{32}$, une traduction de la Déclaration française de 1793 ainsi qu'un court texte où ils définissaient une morale civique empreinte de vertu, de frugalité et de don de soi. L'abolition de l'esclavage formait l'un des buts de l'association ${ }^{33}$.

Roscio formula donc sa requête alors que régnait la peur d'une subversion de l'ordre racialisé. Certains documents du procès témoignent de ce sentiment de menace ${ }^{34}$. Il faut dire que les représentations du candidat s'appuyaient sur une analyse critique de la société coloniale. De

(28) Clément ThiBaud, La Academia de Charcas y la Independencia de América (17761809), traduction d'Andrés Orias Bleichner, Sucre, Archivo y Biblioteca Nacionales de Bolivia, Historia Charcas, 2010, chapitre 5.

(29) Voir Alejandro E. GómEz, « Entre résistance, piraterie et républicanisme. Mouvements insurrectionnels d'inspiration révolutionnaire franco-antillaise sur la Côte de Caracas, 1794-1800 », Travaux et recherches de l'Université de Marne-la-Vallée, nº 11, 2006, p. 91-120.

(30) Manuel Cortés Campomanes, Sebastián Andrés, José Lax. Cf. Pedro Grases, Escritos selectos, Caracas, Biblioteca Ayacucho, 1989, p. 19.

(31) Une liste des conjurés appréhendés par les autorités apparaît dans la « Lista de los Individuos comprendidos en la sublevación de Caracas... », Archivo General de Indias (Séville), Estado, Venezuela, t. 67, $\mathrm{n}^{\circ} 67$ (2g). Voir également Francisco Javier YANEs, Compendio de historia de Venezuela, Caracas, Imprenta de A. Damiron, 1840, p. 127-135.

(32) Archivo General de Indias (AGI), Estado, Venezuela, t. 67, nº 67 (2).

(33) Pedro Grases, La conspiración de Gual y España y el ideario de la independencia, Caracas, Instituto panamericano de Geografía e historia, 1949; Casto Fulgencio LóPEZ, Juan Bautista Picornell y la conspiración de Gual y España, Caracas, Ediciones Nueva Cádiz, 1955; Georges LOMNÉ, « De la República y otras repúblicas : la regeneración de un concepto », Javier FERNÁNDEZ Sebastián (dir.), Diccionario político y social del mundo iberoamericano, Madrid, Fundación Carolina/SECC/CEPC, 2009, p. 1253-1269.

(34) «Censura... », loc. cit., p. 592. 
façon résolument moderne, elles plaidaient en faveur de l'effacement des distinctions raciales. Roscio fit de son cas un test philosophique. Ses arguments n'étaient pas techniques mais des concepts puisés à la pensée des Lumières : les hommes, créés par Dieu à son image, étaient tous égaux. La noblesse n'était pas une qualité héréditaire mais s'appuyait sur le mérite personnel qui, associé à la vertu, fondait les seules hiérarchies légitimes selon un dispositif d'analyse fondé sur le jusnaturalisme moderne et une conception épurée du catholicisme.

«Les hommes sont nés tous libres, [assurait-il en 1798] et ils sont également nobles, car formés d'une même pâte, et créés à l'image et ressemblance de Dieu. [...] Au contraire, le talent et la vertu furent toujours le principe de distinction parmi ces confuses multitudes [turbas] livrées à la liberté et à l'égalité. Et lorsque, fatigués par ce genre de vie si irrationnel et barbare, ils se résolurent à vivre en monarchie ou en république, ils choisirent pour gouvernement de celle-ci ou de celle-là non pas les plus blancs, ni les plus beaux, les plus basanés, ou les plus rosés, mais ceux qui avaient le talent et la vertu $[\ldots] »{ }^{35}$.

Roscio mit en pratique ses convictions. En août 1797, il défendit Isabel María Páez qui était poursuivie pour avoir utilisé un tapis de prière en l'église de Valencia. Or cette pratique était réservée aux femmes blanches de l'aristocratie - les mantuanas - et Isabel María était mulâtresse - parda. L'enjeu d'une telle accusation consistait, dans un contexte où les races et les couleurs étaient mises sens dessus dessous par la Révolution française, à repérer publiquement les limites que ne devaient pas franchir les libres de couleur qui pouvaient prétendre, du fait de leur position sociale, à des marques de prestige réservées jusque-là à l'élite blanche. L'époux d'Isabel María Páez était le notaire ${ }^{36}$ qui avait envoyé au collège des avocats et à l'Audience une copie de l'acte de baptême de Roscio d'où avait disparu la mention de la qualité de sa mère ${ }^{37}$. À cette occasion, le censeur du collège royal, Joaquín Suárez de Rivera, accusa Roscio d'avoir été l'auteur d'un libelle particulièrement séditieux défendant la cause d'Isabel María. La feuille affirmait que la qualité de parda n'interdisait nullement Isabel María à utiliser le fameux tapis des

(35) «Representación de Don Juan Germán Roscio a los Señores Decano y oficiales del ilustre Colegio de abogados de Caracas... ", Caracas, 11 septembre 1798, reproduit dans Santos RODUlfo CORTÉs, op. cit., t. II, p. 130. Italiques originales.

(36) «Censura... », loc. cit., p. 574.

(37) ibid., « Informe del fiscal de la Real Audiencia », 20 mars 1800, p. 489. 
Mantuanas car tous les hommes étaient égaux. Le pamphlet critiquait ouvertement l'ordre racialisés ${ }^{38}$.

L'argument semblait suffisamment scandaleux pour qu'il prouve, aux yeux du collège des avocats, l'implication de Roscio dans la conspiration de 1797. D'autant que le libelle faisait par ailleurs l'éloge de l'humanité des Noirs ${ }^{39}$ - après des siècles de « dégradation » - et appelait de ses vœux une révolution pour l'égalité ${ }^{40}$. L'Audience fit le lien entre ces idées et celles qu'avaient prônées Gual, España, Picornell et leurs amis républicains. Roscio assura être un sujet loyal du roi. Il confessa cependant qu'il se trouvait dans la colonie hollandaise de Curaçao pour accompagner l'envoi de 200 fanègues de cacao au moment où fut rendue publique la conjuration républicaine. Il put s'y procurer les papiers séditieux. Gual se trouvant dans l'île, il lui fit une visite pour le dissuader de continuer ${ }^{41}$. Roscio prétend avoir dénoncé la présence des conjurés aux autorités de Puerto Cabello lors de son retour sur la Terre-Ferme. Il n'y a donc pas de lien transitif entre un discours critique vis-à-vis de la segmentation sociale/ raciale et l'engagement en faveur des «nouveautés » à la française.

D'autant que Roscio inscrivit sa critique dans la tradition romaniste. Des monuments de l'ius civile qu'il enseignait à l'Université, il tenait l'idée que le droit définissait le statut des personnes, non la substance de celles-ci. Ainsi la loi pouvait-elle transformer un Noir en Blanc, car «noir » et « blanc » n'étaient que des représentations du statut juridique. Les fictions sur lesquelles reposaient ces raisonnements pouvaient paraître absurdes aux yeux du commun, elles n'en étaient pas moins « très fondées en raison, justice et équité. $»^{42}$ Cela amenait l'avocat métis à critiquer le principe sur lequel était édifié l'ordre racial. La transmission généalogique des dignités et de l'infamie reposait sur des formalismes juridiques plutôt que sur des fautes originelles transmises de génération en génération. Dès lors, comment ignorer ici le lien de continuité qui existe entre l'expérience sociologique du Créole et son activisme républicain, qui, au cours de la révolution, le fit condamner avec véhémence la monarchie héréditaire et soutenir l'inclusion des libres de couleur à la citoyenneté?

(38) «Censura... », loc. cit., p. 574.

(39) Ibid., p. 583.

(40) Ibid., p. 587.

(41) «Informe del fiscal de la Real Audiencia », 20 mai 1800, reproduit dans Hector PARRA MÁrquez, op. cit., p. 502-504.

(42) « Información de calidad del Dr. Juan Germán Roscio », dans Santos Rodulfo CorTés, op. cit., p. 138. 


\section{1}

Lors de la révolution, Juan Germán Roscio se révéla un patriote infatigable. Il joua un rôle central dans la proclamation de la Junte Suprême de Caracas qui fut le premier gouvernement autonome de l'Amérique espagnole. À la nouvelle de l'invasion de l'Andalousie par les troupes françaises, fut convoquée une assemblée municipale extraordinaire destinée à statuer sur l'attitude à adopter. Ce 19 avril 1810, il y avait grande 《 concurrence du peuple $»^{43}$ sur la place d'armes, bien au-delà des pères de famille usuellement présents. Ce peuple désigna les docteurs Juan Germán Roscio et Félix Sosa comme députés. Les avocats patriotes furent chargés de porter la parole de l'assemblée aux membres de l'Ayuntamiento et au capitaine général Emparan qui siégeaient dans la salle capitulaire de l'hôtel de ville. Un peu plus tard dans la journée, Roscio escorta les auditeurs de l'Audience avec quelques soldats. Puis il signa l'Acte de formation de la première junte d'autogouvernement qui défendait les droits de Ferdinand VII, alors captif à Valençay ${ }^{44}$. La désignation de Roscio à la fonction de représentant du peuple indiquait, semble-t-il, que son prestige débordait le cercle des élites auxquelles il avait fini par appartenir ${ }^{45}$. Le député devint l'une des figures les plus importantes des institutions autonomes puis indépendantes dont se dota le Venezuela entre 1810 et 1812. Chargé des affaires étrangères au sein du premier gouvernement provisoire, il rédigea le premier règlement électoral pour le congrès de $1811^{46}$. Il joua en tant que député un rôle important dans le processus qui mena à la déclaration d'indépendance du 5 juillet, qu'il rédigea. Il intégra la commission destinée à préparer la constitution confédérale, adoptée en décembre. Au cours de la « période critique » de l'année 1812, il fit partie du tribunal devant lequel comparurent les auteurs de la « révolution de Valencia ${ }^{47} \gg$ contre l'indépendance et la république. Après avoir participé à l'exécutif collégial de la confédération, Roscio fut ensuite choisi

(43) José Manuel Restrepo, Historia de la Revolución de la República de Colombia en la América meridional, Bogotá, Villegas, 2009 [1827,1858], t. I, p. 525.

(44) Francisco Javier YANES, op. cit., p. 80-82.

(45) Même si, au cours de la journée du 19 avril, Roscio et Sosa sont accusés de n'avoir pas bien exprimé la volonté du peuple, ibid., p. 80.

(46) Juan Germán Roscio, « Alocución y reglamento para la elección de diputados al primer congreso de Venezuela », 11 juin 1810 dans José Félix Blanco et Ramón AzPurua (éd.), Documentos para la historia de la vida pública del Libertador, Caracas (désormais BA), 1875-1877, t. II, p. 504512. Sur la conception de la citoyenneté, voir Véronique HÉBRARD, Le Venezuela indépendant. Une nation par le discours, Paris, L'Harmattan, 1996, p. 102-119.

(47) Révolte loyaliste regroupant des officiers, des clercs ainsi que de nombreux Pardos. 
par Francisco de Miranda pour le conseiller dans le cadre de la loi martiale, en mai $1812^{48}$. Ces états de service révolutionnaires lui valurent un traitement cruel lorsqu'il fut appréhendé par les armées royalistes ${ }^{49}$. Le gouverneur militaire de Caracas, Pascual Martínez, l'exhiba ceps aux pieds comme un criminel de droit commun. Les députés américains des Cortes se cotisèrent pour le vêtir et le nourrir dans sa prison de Cadix ${ }^{50}$. Des décennies plus tard, Roscio se souviendrait de ces humiliations et de ses semaines d'emprisonnement à la Guaira, « dans le cachot le plus immonde et obscur, [avec] les fers $»^{51}$. On comprend sa haine des libéraux espagnols.

Le parcours révolutionnaire de Roscio concerne l'articulation de deux problèmes majeurs qui se posèrent aux patriotes. Comment définir, d'une part, la communauté civique héritière d'une société divisée en « classes », c'est-à-dire en corps racialisés? Comment, d'autre part, construire un gouvernement autonome, indépendant puis républicain qui n'apparaisse pas comme impie au plus grand nombre? L'indépendance créait, de facto, une république qui rompait avec la monarchie catholique, cet empire universel chargé par Rome de répandre partout l'Évangile. La rupture du lien avec l'Espagne impliquait, d'une part, la recomposition des principes les plus anciens de la légitimité politique et, d'autre part, la reconfiguration de la société coloniale par la citoyenneté égalitaire - esclaves exclus. Or la leçon d'Haïti, qui était présente dans tous les esprits, montrait que la transmutation des fondements de l'ordre, dans des sociétés pigmentocratiques, comportait le risque d'une "guerre des couleurs » comme on allait la nommer à l'occasion du procès du général mulâtre Piar en $1817^{52}$.

Le mois de juillet 1811 noua toutes ces tensions. Jusque-là, Roscio avait incarné la modération dans le développement de « l'heureuse révolution » de Caracas. Son règlement électoral de juin 1810 distinguait

(48) José Manuel Restrepo, op. cit., t. I, p. 617.

(49) La capitulation signée entre Monteverde et Miranda interdisait pourtant cet emprisonnement.

(50) Juan Germán Roscio, «Artículo comunicado », Correo del Orinoco, n 72, 22 juillet 1820.

(51) «Extracto de una noticia de la Revolución que sirve de introducción a la historia de los padecimientos del doctor Roscio, escrita por él mismo » 31 décembre 1812, Testimonios de la época emancipadora, A. Uslar Pietri (comp.), Caracas, Academia Nacional de la Historia, 1961, p. 145-170, ici p. 163.

(52) Simón Bolívar, « Manifiesto del Jefe Supremo a los Pueblos de Venezuela », 5 juillet 1817, Doctrina del Libertador, op. cit., p. 71. Cf. Marixa LAsso, « Race War and Nation in Caribbean Gran Colombia, Cartagena, 1810-1832 », American Historical Review, n 111-2, 2006, p. 336-361. 
ainsi citoyens actifs et passifs. Les premiers correspondaient en réalité aux « bourgeois »-vecinos - de l'Ancien Régime, définis par leur sexe (« on exclura [de la liste] les femmes »), leur statut matrimonial, leur âge, leur mode de vie (« avoir maison ouverte ou habitée »), leur indépendance financière, leur réputation et leurs propriétés ${ }^{53}$. Plus tard, il montra les plus grandes réserves à propos de la Société Patriotique qui voulait radicaliser la révolution. Ce club, patronné par Miranda, mêlait Pardos et aristocrates comme « les Toro, les Ribas Herrera et les Bolivar $»^{54}$. Des femmes y étaient admises. En juin 1811, dans une lettre à Andrés Bello, Roscio déplorait que la Société patriotique connaisse une « certaine effervescence pour le système de l'égalité ou démocratie $\|^{55}$. Il s'y moquait du « cercle patriotique » du Créole universel.

Le $1^{\text {er }}$ juillet, une « Déclaration des droits du Peuple» fut adoptée par le Congrès ${ }^{56}$. Roscio ne manqua pas de parapher le document, lui qui estimait que la connaissance de ces droits constituait le cœur même d'une société juste, le fondement de tout gouvernement libre, la visée de toute révolution réussie. À ce premier pas succéda un second tout à fait extraordinaire. La tâche fondamentale du congrès, réuni depuis mars, était de constituer une confédération des provinces vénézuéliennes. Il fallait former une union puissante vis-à-vis de l'extérieur tout en sauvegardant les droits de souveraineté face aux appétits des puissances, à la Régence espagnole, à Joseph Bonaparte. Cette équation impliquait des solutions nouvelles et radicales, comme Fernando Peñalver le dit à la tribune en s'inspirant de Montesquieu :

«Voyons quel type de gouvernement nous désirons. Le Monarchique? Non, parce que nous avons souffert trois cents ans de tyrannie et nous abhorrons les Rois. L'Aristocratique nous convient-il? Non plus, parce que c'est le pire de tous les gouvernements. Nous voulons sans doute une République fédérale Démocratique? Celui-ci exige que son territoire soit divisé en petites Républiques, et que toutes réunies par une

(53) «Alocución y reglamento para la elección... », chap. I, art. IV, loc. cit.

(54) Roscio à Bello, 9 juin 1811, dans Obras, Caracas, Publicaciones de la Secretaría general de la Décima conferencia interamericana, 1953, t. III, p. 26. Voir sur ce point les longs développements de Caracciolo PARra-PÉrez, Historia de la Primera República de Venezuela, Caracas, Biblioteca Ayacucho, 1992, t. I, p. 282-286.

(55) Carole Leal Curiel, « Tensiones republicanas. De patriotas, aristócratas y demócratas : la Sociedad Patriótica de Caracas », Guillermo Palacios (coord.), Ensayos sobre la nueva historia política de América Latina, siglo XIX, México, El Colegio de México, 2007, p. 241-244.

(56) Dans sa session législative pour la province de Caracas. Le texte de la Déclaration est reproduit dans Los derechos del hombre, Caracas, Academia Nacional de la Historia, 1959, p. 93-101. 
Représentation commune qui la confédère, elles forment un seul État et Souveraineté dans les matières qui assurent la liberté et l'indépendance commune $»^{57}$.

Après le 3 juillet, les sessions du congrès portèrent sur le statut de cette confédération en regard du droit des gens. Au fil des interventions, le consensus se forma autour de l'idée que la confédération n'était possible que si les provinces qui la formaient étaient des corps politiques émancipés ${ }^{58}$. Pendant la discussion, Roscio se montra d'une grande prudence. Il souleva plusieurs arguments contre l'indépendance immédiate, même s'il loua l'exemple des États-Unis. L'historiographie traditionnelle a fait de lui un adversaire de l'émancipation mais, comme l'a montré Caracciolo Parra-Pérez ${ }^{59}$, le député de Calabozo cherchait, par ses objections, à mieux cerner les enjeux du débat. Ses interventions portaient sur la faiblesse de la population et sur les problèmes religieux qu'une telle indépendance soulèverait. Ce dernier point augurait d'un tournant fondamental dans la pensée de Roscio puisque l'essentiel de son travail de publiciste serait désormais consacré à prouver la possibilité d'une république catholique. De façon surprenante, il affirma que «l'indépendance [consistait] en ne dépendre d'aucune nation étrangère, et non [...] en l'abolition du Gouvernement Monarchique et l'établissement du Républicain [...] ${ }^{60}$. Roscio craignait la rupture brutale avec l'Espagne comme beaucoup d'autres députés. À cette date, il n'avait jamais professé publiquement un quelconque républicanisme antimonarchique. La forme du régime fut d'ailleurs le point aveugle des débats. L'émancipation fut votée le 5 juillet 1811. Roscio fut chargé par le Congrès de rédiger l'acte d'indépendance de la «Confédération américaine du Venezuela dans le continent méridional » qui ne précisait pas la forme du gouvernement ${ }^{61}$. Quelques mois plus tard, la constitution des Provinces-Unies ne levait que fort discrètement l'ambiguïté en employant le mot de « républicain », en une occurrence enfouie à l'article 133.

(57) Séance du 18 juin 1811 citée par Carole Leal, Carolina Guerrero, Elena Plaza, « República - Venezuela », Javier Fernández Sebastián (dir.), loc. cit., p. 1371.

(58) Session du 3 juillet, BA, III, p. 129. «Polité », démarqué de l'anglais polity, désigne une communauté disposant d'un gouvernement autonome ou indépendant, État, province ou cité. Le terme, souvent utilisé par les historiens de la Révolution américaine, renvoie au processus d'indépendance et de constitutionnalisation des colonies en États après 1776. Son usage est indiqué ans le contexte de la Terre-Ferme dans la mesure où il ne se rapporte pas seulement au niveau étatique mais désigne les niveaux inférieurs de souveraineté, comme les cités.

(59) Caracciolo Parra-PÉreZ, op. cit., p. 301-310.

(60) Session du 3 juillet 1811, BA, III, p. 132.

(61) «Acta de Independencia », 5 juillet 1811, BA, III, p. 170. 
On peut formuler l'hypothèse suivante : ce fut la réaction populaire face à la sécession qui précipita l'adhésion du député de Calabozo comme du gouvernement confédéral au républicanisme radical. Le 10 juillet, une soixantaine de Canariens se soulevèrent en effet pour le roi et la vierge du Rosaire à Los Teques, près de Caracas ${ }^{62}$. Deux jours plus tard, la fidèle cité de Valencia leva l'étendard de Castille contre le gouvernement. La rébellion se développa au nom du roi Ferdinand et de la défense du catholicisme. L'on trouvait des créoles mais surtout des Pardos et des esclaves parmi les insurgés. Il fallut envoyer une colonne sous la direction de Miranda pour mater la rébellion. Le Congrès estima que ces résistances étaient suscitées par les prêtres et les péninsulaires - ennemis de l'intérieur. Le député Yanes, reproduisant une opinion courante, dénonça la croisade des curés de Valencia contre les « gens hérétiques et impies de Caracas ${ }^{63}$. Selon lui, ces prêtres « [répandaient] qu'il n'y avait pas de religion à Caracas, qu'on ne baptisait pas les enfants, que l'archevêque était prisonnier et blessé ${ }^{64}$, et autres sornettes semblables $»^{65}$. Commençait une guerre civile autour de la forme du régime et de la question religieuse qui prenait les contours d'un conflit de couleurs.

Le Congrès réagit en ouvrant la citoyenneté aux libres de couleur pour éviter qu'ils ne basculent du côté royaliste. Son président, Yanes, défendit l'égalité des droits entre blancs et libres de couleur pour éviter l'abîme :

«L'on ne doit craindre des commotions que si nous ne traitons les Pardos avec mépris ou indifférence, car la justice donnera une impulsion irrésistible à cette classe - qui est beaucoup plus nombreuse que la nôtre. [...] Les Pardos sont instruits, ils connaissent leurs droits, ils savent que par la naissance, la propriété, le mariage [...] ils sont les fils du pays; qu'ils ont une Patrie qu'ils doivent défendre, et dont ils doivent attendre les récompenses lorsque leurs actions le méritent ${ }^{66}$.

C'était souligner la capacité politique des Pardos que l'expérience révolutionnaire avait démontrée. En décembre, la loi fondamentale des

(62) Francisco Javier YANes, op. cit., p. 116.

(63) Ibid.

(64) Il participa en réalité aux cérémonies du serment à l'indépendance.

(65) Francisco Javier Yanes, op. cit., p. 116.

(66) Session du 31 juillet 1811, Libro de actas del Supremo Congreso de Venezuela, Caracas, Academia Nacional de la Historia, 1959, t. III, p. 140. 
Provinces-Unies effaça la ligne de couleur entre les Pardos et les autres citoyens. La citoyenneté, en éliminant les métis comme " classe » séparée, devait poursuivre la régénération patriotique de ce groupe. C'était une voie opposée à celle de la Constitution espagnole de Cadix qui exclut les Afrodescendants des droits politiques en mars 1812.

\section{La république catholique et les Pardos}

Les patriotes avaient anticipé les résistances populaires à l'indépendance. En une vision paternaliste de la société, ils estimaient que les peuples étaient ignorants de leurs droits par la corruption du despotisme et son alliance avec la religion établie. Ces représentations étaient bien évidemment racialisées et se focalisaient sur la «question des Pardos » selon l'expression d'Alejandro E. Gómez ${ }^{67}$. La superstition, l'ignorance, les habitudes de servilité et d'adulation décrivaient les populations afrodescendantes et métisses, libres ou serves, selon un préjugé déjà ancien. Cette grille d'interprétation se vérifiait avec la « révolution de Valencia ». Elle se renforça lors du soulèvement des esclaves et des Pardos des vallées orientales de Caracas contre la république en 1812. La rébellion royaliste des Llaneros mulâtres et zambos des plaines de l'Orénoque, fin 1813, fixa l'image de multitudes luttant contre leur liberté au nom du roi et d'une forme pervertie de catholicisme. C'était oublier que la propagande espagnole promettait aux esclaves l'émancipation contre l'engagement militaire. Les libres voyaient réalisée l'une de leurs plus anciennes revendications avec la fin des discriminations légales à l'entrée des grandes corporations ${ }^{68}$. L'accès aux privilèges des Blancs, promis par les royalistes, valait peut-être mieux que la loi commune des républicains : la première était simple à saisir parce qu'elle s'inscrivait dans des luttes anciennes tandis que l'égalité républicaine correspondait à d'autres horizons politiques et intellectuels. Et puis le camp royaliste était tout aussi libéral que le confédéré car la péninsule faisait sa « révolution de nation ${ }^{69}$ à Cadix.

(67) Alejandro E. Gómez, «The 'Pardo Question'», Nuevo Mundo Mundos Nuevos, Materiales de seminarios, 2008, [En línea]. URL : http://nuevomundo.revues.org/34503. Consulté le 29.X.2010.

(68) Disposition du 29 mars 1812. José Ceballos, capitaine général du Venezuela, au secrétaire d'État, 22 juillet 1815, AGI, Gobierno, Caracas, leg. 109, dans James F. KING, « A Royalist View of the Colored Castes in the Venezuelan War of Independence », Hispanic American Historical Review, no 33-4, 1953, p. 533.

(69) José María Portillo VAldés, Revolución denación : orígenes dela cultura constitucional en España 1780-1812, Madrid, Centro de Estudios Constitucionales, 2001. 
Maints Pardos se rangèrent néanmoins sous la bannière républicaine et les unités patriotes étaient peuplées de libres de couleur.

Face aux soulèvements royalistes et au refus des provinces de Maracaibo, Coro et Guayana de se joindre à la confédération, l'opinion patriote se radicalisa, adoptant un républicanisme virulent. L'option était inattendue dans la mesure où la monarchie catholique n'ignorait pas la notion de république, comme l'ont souligné José María Iñurritegui, Annick Lempérière et Jean-Frédéric Schaub ${ }^{70}$. Soucieux du Bien commun, l'Empire s'appuyait sur un ordre corporatif dont les municipalités représentaient les éléments centraux. La documentation coloniale nomme souvent « républiques » les cités et leurs habitants, « républicains ». La déclaration d'indépendance et la dynamique de polarisation qui s'ensuivit récusèrent ce républicanisme monarchique. Plusieurs indices témoignent de cette évolution, au premier rang desquels la réhabilitation publique de la conspiration républicaine de 1797. À Caracas, lors des célébrations de l'acte d'indépendance le 14 juillet, la prise d'armes honora les deux fils d'España qui portaient l'étendard du premier bataillon de ligne alors que l'on hissait le drapeau arc-en-ciel de Miranda ${ }^{71}$. Les papiers de la sédition, incluant la Déclaration des droits de l'homme avec diverses maximes républicaines, bénéficièrent d'une réimpression quasi officielle à Caracas ${ }^{72}$. La bataille pour gagner l'opinion des Pardos passait, aux yeux du Congrès, par l'adoption du régime républicain. Celui-ci avait le double avantage d'être égalitaire et de rejeter le principe de la succession héréditaire - et donc, par extension, toute transmission généalogique d'une quelconque infériorité juridique, comme l'avait signalé l'un des articles républicains du complot de 1797 :

« L'égalité naturelle entre tous les habitants des Provinces et districts est déclarée et la plus grande harmonie doit régner entre les Blancs, les Indiens, les Pardos et les Morenos, lesquels doivent se voir comme frères en Jésus-Christ, égaux par Dieu, les avantages des uns et des autres ne découlant que du mérite et de la vertu, qui sont les deux seules distinctions

(70) José María IÑURritegui RodríGuEZ, La gracia y la república. El lenguaje político de la teología católica y el Príncipe cristiano de Pedro de Ribadeneyra, Madrid, UNED, 1998; Annick LEMPÉRIÈRE, Entre Dieu et le roi, la république, Mexico XVI ${ }^{e}$-XIXe siècles, Paris, Les Belles Lettres, 2004 et Jean-Frédéric Schaub, «El pasado republicano del espacio público », François-Xavier Guerra et Annick Lempérière (éd.), Los espacios públicos en Iberoamérica, México, FCE, 1998, p. 27-53.

(71) Francisco Javier YANES, op. cit., p. 117.

(72) Derechos del Hombre y del Ciudadano, con varias máximas republicanas y un discurso preliminar dirigido a los americanos, Caracas, Imprenta de J. Baillio y comp., 1811 
réelles et véritables qui existent parmi les hommes et la seule qui distinguera les individus de notre République $\gg^{73}$.

La république de Gual et España, comme celle de Roscio et Miranda, était agréable à Dieu, source et garant de l'égalité. Common Sense, publié quelques mois avant la Déclaration d'indépendance nordaméricaine, n'avait-il pas montré que Yahvé détestait tellement les rois qu'il avait imposé la monarchie aux juifs pour les punir de leurs péchés. Pendant la révolution, le patriote Manuel García de Sena publia une traduction espagnole de Paine dont certains passages, particulièrement antimonarchiques, furent reproduits dans la Gazeta de Caracas en janvier $1812^{74}$. Le gouvernement royal y apparaissait tour à tour comme une invention des païens ou du diable. « [Le] titre de Majesté royale et sacrée appliquée à un ver » s'y révélait particulièrement impie ${ }^{75}$.

Roscio fut l'un des principaux protagonistes de cette républicanisation de la confédération. Son manifeste, le Patriotisme de Nirgua et abus des rois, fut publié en septembre 1811 sous la forme d'un opuscule ${ }^{76}$ avant d'être repris dans la presse. Cette intervention répondait à plusieurs contextes en nouant différents enjeux du républicanisme en Terre-Ferme. Il y avait tout d'abord la controverse sur la tolérance religieuse, lancée par un article de « William Burke ». Mario Rodríguez estime que ce pseudonyme, déjà utilisé pour répandre les idées de Miranda, cache en réalité Juan Germán Roscio ${ }^{77}$. À partir de février 1811, « Burke » publia une série d'articles dans la Gazeta de Caracas en faveur de la reconnaissance officielle de la pluralité des cultes. Ces textes suscitèrent de fortes réactions dans toutes les couches de la société. Roscio signale par exemple que ses idées déplacèrent le débat public sur les questions religieuses alors qu'il s'était dangereusement fixé sur les pétitions égalitaires des Pardos. Il rapporte aussi qu'à la lecture de la Gazeta de Caracas, Miranda se précipita

(73) Article 32 des « Ordenanzas », dans Pedro Grases, La conspiración de Gual..., op. cit., p. 51.

(74) « Política. De la Monarquía y sucesión hereditaria : tomado de la obra de Tomás Payne, sobre justificar la Independencia de la Costa Firme... ", Gazeta de Caracas, 14 janvier 1812 et 17 janvier 1812 .

(75) Ibid., 14 janvier 1812. Il s'agit de la traduction fidèle d'un passage de Common Sense, New York, Cosimo Classics, 2006, p. 9.

(76) Patriotismo de Nirgua y abuso de los reyes, Caracas, En la Imprenta de Juan Baillío, 1811. Le document porte la mention « Dans le Palais fédéral du Venezuela », daté du 18 novembre 1811 et porte les initiales J.G.R. Il fut repris dans numéro 15 d'El Observador caraqueño.

(77) Mario Rodríguez, "William Burke » and Francisco de Miranda: The Word and the Deed in Spanish America's Emancipation, Lanham, University Press of America, 1994. 
chez l'archevêque et fit expulser «Burke» de la Société Patriotique ${ }^{78}$. Tour à tour, les Franciscains de Valencia, le médecin Antonio Gómez, puis l'Université de Caracas défendirent publiquement l'intolérance religieuse, conséquence naturelle de la vérité du catholicisme ${ }^{79}$. Le thème était en vérité explosif. Défendant «Burke», Roscio fit preuve d'un grand courage puisqu'il attaqua l'autorité des papes en matière politique. Il fit même l'éloge du tyrannicide en s'appuyant sur l'hérétique Wyclif, ce que lui reprocha plus tard son frère José Félix, curé de Puerto Cabello, pourtant considéré comme un « jacobin consommé ${ }^{80}$.

Le deuxième élément contextuel était la réaction de la société visà-vis de la rupture avec la monarchie espagnole. Le congressiste louait dans l'opuscule l'attitude de la petite cité de Nirgua, située entre Valencia et Barquisimeto. Après avoir suivi la révolte valencienne pendant trois jours, celle-ci avait choisi le « chemin de la vérité » pour jurer l'indépendance. Les responsables du mauvais pas étaient désignés: des « ecclésiastiques réguliers et séculiers de Valencia » qui préparaient la confédération aux «tirs napoléoniens sous couvert du nom abominable de Ferdinand VII $»^{81}$. Et puis Nirgua n'était pas n'importe quelle cité. Elle possédait en effet un corps de ville composé exclusivement de Pardos et de Morenos depuis le début du XVII ${ }^{\mathrm{e}}$ siècle ${ }^{82}$. Ce choix était lourd de sens : l'offre d'égalité, que comportait le régime républicain, était adressée avant tout aux Pardos. Ces derniers étaient dignes de la liberté comme en témoignait le juste comportement du cabildo « noir » de Nirgua pendant la révolution. Ils étaient capables d'autogouvernement et devaient aimer la république : c'était le seul régime qui effaçait toute distinction de « race » car « l'uniformité de couleur [...] soutenait le système républicain parmi les descendants d'Adam et de Noé $»^{83}$. Tout gouvernement

(78) Roscio à Bello, 9 juin 1811, loc. cit. L'allusion à Burke est incompréhensible s'il s'agit d'un pseudonyme comme l'affirme Rodríguez.

(79) L'ensemble des textes est disponible dans La libertad de cultos, Caracas, Academia Nacional de la Historia, 1959.

(80) «Causa de infidencia de José Félix Roscio, Presbítero doctor, cura párroco y vicario foráneo de Puerto Cabello », Causas de infidencia, Caracas, Academia Nacional de la Historia, 1960, t. II, p. 11-47, ici p. 12 (José María Atencio), et p. 27 (José Félix Roscio).

(81) « Patriotismo de Nirgua... », Pensamiento político..., op. cit., p. 66.

(82) Irma Marina Mendoza, « El cabildo de Pardos en Nirgua, siglos XVII y XVIII », Anuario de estudios bolivarianos, $\mathrm{n}^{\circ}$ 4-4, 1995, p. 95-120 et Frédérique LANGuE, «'El indiano de la comedia es moreno' ou de la multitude servile à l'aristocratie blanche, Venezuela, XVI ${ }^{\mathrm{e}}-\mathrm{XVIII}{ }^{\mathrm{e}} \mathrm{s}$. », Bernard LAVAllé (dir.), Transgressions et stratégies du métissage en Amérique coloniale, Paris, Presses de la Sorbonne Nouvelle, 1999, p. 223-248.

(83) « Patriotismo de Nirgua... », Pensamiento politico..., op. cit., p. 68. 
qui l'ignorerait devait susciter la vengeance du « canon, de l'acier et du cannabis $»^{84}$, à partir duquel on produisait le drap grossier qui habillait les pauvres Pardos et les esclaves de Terre-Ferme.

L'enjeu religieux était intimement mêlé à cette bataille pour gagner l'opinion des Pardos. Il fallait prouver que la république était un régime compatible avec le catholicisme. Dans cette perspective, Roscio avança les arguments habituels à propos des républiques antiques et modernes, la nullité de la bulle inter cetera, la violence de la Conquête. Mais il alla plus loin en proposant, pour la première fois, une argumentation théologique serrée pour montrer, à travers une lecture de la Bible, que le meilleur régime aux yeux de Dieu n'était pas le monarchique. "Vivre sans roi n' [était] pas un péché ${ }^{85}$. Le docteur de Caracas se mettait à l'école de Paine mais sa réflexion signalait aussi une influence janséniste. Le Nouveau Testament, invoqué pour prouver le droit divin direct des rois, était en réalité « une déclaration des droits de l'homme et des peuples » ${ }^{86}$. « La doctrine de Jésus-Christ » prouvait l'égalité primitive des hommes. Mais c'était l'Ancien Testament qu'il fallait consulter pour comprendre la politique voulue par Dieu. Que montrait le Pentateuque? Que « le gouvernement républicain fut le premier parce qu'il [était] le plus conforme à la nature de l'homme »? En une manœuvre courante dans le monde catholique, le jusnaturalisme moderne était réconcilié avec les Écritures dans une démonstration aux accents protestants. En juillet 1811, Roscio avait déjà eu recours à l'histoire sacrée lorsqu'il avait écrit le Manifeste que fait au monde la confédération du Venezuela ${ }^{87}$. Il y prouvait le droit de résistance des patriotes en mobilisant les livres historiques de l'Ancien Testament.

La chute de la première confédération, puis du régime rétabli par Bolívar en 1813, confirmaient les craintes des premiers patriotes. Les insurgés se battaient en arborant l'étendard de la vierge du rosaire au cri de «Vive le roi, vive la religion! ». Pis, le tremblement de terre du 26 mars 1812, jeudi saint, comme le jour de la proclamation de la Junte Suprême en 1810, fut interprété comme une punition de la Providence. Ces désastres renforcèrent les convictions républicaines de Roscio. Il fallait, aux yeux du peuple, que la religion ne soit pas l'ennemie des confédérés. Après la capitulation de Miranda, Roscio rédigea en captivité le

(84) Ibid., p. 80.

(85) Ibid., p. 67.

(86) Ibid., p. 73.

(87) Juan Germán Roscio, « Manifiesto que hace al mundo la confederación de Venezuela en la América meridional... », 30 juillet 1811, BA, III, p. 189-206. 
manuscrit de son Triomphe de la liberté sur le despotisme. Libéré en 1815 grâce à l'intercession des Anglais après une évasion vers Gibraltar, il rejoignit Philadelphie en 1817 via la Jamaïque et la Nouvelle-Orléans.

\section{La République selon les Écritures saintes ${ }^{88}$}

La ville de Benjamin Franklin était l'une des capitales de la cause patriote, bien mal en point puisque seul le Rio de la Plata résistait alors aux troupes du roi ${ }^{89}$. Parmi les 60000 Philadelphiens, on comptait maints patriotes hispano-américains ${ }^{90}$. Manuel Torres était l'un des piliers de ces sociabilités de l'exil. Il avait été poursuivi à la suite de la traduction des Droits de 1'Homme à Bogotá en 1794 et dut s'installer aux États-Unis deux ans plus tard. Il devint, après 1810, l'intermédiaire diplomatique entre les patriotes et le gouvernement américain. Il fut l'agent de Carthagène puis chargé d'affaires du Venezuela en 1818. Roscio devint l'ami intime de Torres qui l'aida à publier son manuscrit ${ }^{91}$. Sous l'impulsion du journal de William Duane, Aurora, et d'imprimeurs engagés comme Jean-François Hurtel, Thomas et George Palmer, Philadelphie était devenue l'une des cités phares du républicanisme hispanique. Beaucoup d'ouvrages antiespagnols et pro-républicains sortirent des presses pennsylvaniennes comme ceux de Santiago Puglia, José Alvarez de Toledo, Manuel Palacio Fajardo, Manuel Torres, et, après Roscio, Vicente Pazos Kanki et Vicente Rocafuerte $^{92}$. Roscio trouvait à Philadelphie un cadre idéal pour l'impression de son manuscrit, quarante ans après le pamphlet de Paine qui eut une telle influence sur la Révolution américaine.

(88) Nous avons développé cette réflexion en collaboration avec María Teresa Calderón, du Centre d'Études en Histoire de l'Université Externado de Colombie. Pour le sous-titre, nous paraphrasons le titre de 1'article que François-Xavier Guerra a consacré, à Locke, Bossuet et Roscio, «'Políticas sacadas de las sagradas Escrituras'. La referencia a la Biblia en el debate político (siglos XVII a XIX) », Mónica QuiJada et Jesús Bustamante (coords), Elites intelectuales y modelos colectivos : mundo ibérico (s. XVI-XIX), Madrid, CSIC, 2003, p. 155-198.

(89) Monica Henry, «Les premières publications révolutionnaires des exilés hispanoaméricains aux États-Unis », Transatlantica [En ligne], 2-2006, Consulté le 26 octobre 2010. URL : http://transatlantica.revues.org/index1146.html.

(90) Rafael RoJAs, "Traductores de la libertad: el americanismo de los primeros republicanos », Carlos Altamirano (dir), Historia de los intelectuales en América Latina, Buenos Aires, Katz, 2008, p. 217-219. p. $140-141$.

(91) Ducoudray-Holstein, Histoire de Bolivar, Paris, Alphonse Levasseur libraire, 1831, I,

(92) Nicolás Kanellos, «José Alvarez de Toledo y Dubois and the Origins of Hispanic Publishing in the Early American Republic », Early American Literature, no 43-1, 2008, p. 83-100, avec une liste de ces publications p. 84-86. 
L'ouvrage mériterait une longue analyse. Contrairement à Common Sense, Le Triomphe ne vise pas tant à édifier les foules qu'à prouver la république chrétienne de façon quasi dogmatique ${ }^{93}$. Il s'agit d'un ouvrage épais, touffu et complexe, rédigé dans un style dense. Écrit en prison, le livre adopte la forme d'une confession où Roscio prend Dieu à témoin et le tutoie. La référence à saint Augustin s'accompagne d'une volonté explicite de faire retour au texte de l'Ancien Testament. Il suit la trace des polémistes républicains d'Amérique du Nord, considérant que les textes vétérotestamentaires fournissent des « documents politiques » à caractère historique ${ }^{94}$. Roscio s'intéresse particulièrement aux deux livres de Samuel qui décrivent l'origine de la royauté de Saül et David. Mais il commente également le Pentateuque, citant les ouvrages « historiques» de "l'Exode, Josué, Juges, Rois, Paralipomenon, Esdras, Néhémie et les Maccabées ». Ces trois dernières sections illustraient la résistance juive à l'oppression. Les livres sapientiaux, poétiques ou prophétiques furent également mobilisés d'autant que les Psaumes ou les Proverbes servaient traditionnellement à exalter le pouvoir divin des rois ${ }^{95}$.

Pour démontrer sa thèse, Roscio s'attaqua au montage dogmatique de la majesté monarchique. Il voulut en montrer la fausseté par une analyse linguistique subtile. Il dénonçait les pouvoirs de la métaphore liant le mot « ROI» au divin, le corps charnel du roi au corps mystique de la monarchie et au Christ. Ce dispositif produisait, à ses yeux, une image qui saisissait l'âme des sujets. La majesté reposait sur une image de la légitimité se donnant comme le reflet réel de la source divine (d'où son rapport avec la transsubstantiation). Elle constituait ainsi un dévoiement de la religion et une forme particulièrement grave d'idolâtrie qui « sanctifi[ait] le despotisme $»^{96}$. C'est pourquoi Roscio eut recours aux récits vétérotestamentaires, pour défaire le nœud métaphorique - et théologico-politique - entre Dieu et le roi : raison de la narration contre magie des images. Il disqualifiait les Évangiles comme source de réflexion sur le gouvernement : Jésus-Christ était avant tout un libérateur spirituel ${ }^{97}$. Il critiquait ainsi l'usage que firent les apologistes de l'absolutisme de

(93) Cette partie a fait l'objet d'une communication à la conférence organisée par Rebecca Earle : « Writing the Republic : Historical Writing in Nineteenth-Century Spanish America », Université de Warwick (7-8 novembre 2008).

(94) Juan Germán Roscio, El triunfo..., op. cit., p. 4.

(95) François-Xavier Guerra, « Políticas... », loc. cit., p. 159.

(96) Juan Germán Roscio, El triunfo..., op. cit., p. 5.

(97) Ibid., p. 112 par exemple. 
Matthieu 22, 21, Romains 13,1 et des épîtres de Paul. Roscio s'attaquait au droit divin direct des Rois, qui était en Espagne une doctrine relativement nouvelle, affirmée après les émeutes madrilènes de 1766. Il dégageait les différents types d'autorité présents dans la Genèse et les livres de l'Exode, où, suivant Paine, il tenait le gouvernement des Patriarches pour démocratique puis aristocratique. Il soulignait, à travers Néhémie, que la monarchie était un châtiment de Dieu, que Gédéon, après avoir triomphé des Madianites et tué plusieurs rois, repoussa la couronne. Il rappelait que Moïse avait exécuté les rois Sehon et Og et que Josué massacra 31 rois $^{98}$. Après avoir prouvé la légitimité du tyrannicide, il fondait la souveraineté du peuple par de longs développements sur le Deutéronome (Dt 17,14-15). Il disqualifiait également les métaphores généalogiques dont il dénonçait la « manie coloniale ». Le roi n'était pas plus le père de ses sujets que l'Espagne la mère de l'Amérique. Il objectait le pouvoir patriarcal. C'était un point fondamental car les montages généalogiques assuraient également la stratification raciale de la société coloniale. En critiquant le principe même de l'argument généalogique et patriarcal, Roscio déconstruisait les fondements racialisés de l'ordre impérial.

La critique de la hiérarchie ecclésiastique et des prétentions temporelles de la papauté donnaient un tour janséniste et crypto-protestant au Triomphe. Cela correspondait à l'environnement intellectuel de l'époque puisque les auteurs des «Lumières catholiques » étaient appréciés en Amérique hispanique (Febronius Muratori, Ricci, Van Espen et même Fleury $)^{99}$. Roscio reprenait en filigrane certains éléments des théories anti-romaines - jansénisme, gallicanisme, conciliarisme, épiscopalisme pour montrer que l'autorité légitime était toujours ascendante (du corps à la tête) et non descendante. Dans cette perspective, Roscio, à l'égal des jansénistes, ne manqua pas d'exalter les premiers temps « démocratiques » de l'Église où les fidèles élisaient leurs évêques. « Je vois dans l'Église naissante, écrit-il, une forme de gouvernement si populaire que même les femmes avaient le droit de vote dans les assemblées ${ }^{100}{ }^{10}$. L'avocat remplaçait la majesté royale par la «majesté du peuple ${ }^{101}$. Celleci serait la médiatrice sublunaire de la volonté de Dieu, les rois n'étant

(98) Ibid., p. 201.

(99) María Teresa Calderón et Clément Thibaud, La Majestad de los pueblos en la Nueva Granada y Venezuela 1780-1832, Bogotá, Madrid, México, Taurus Historia, 2010, chapitre 4.

(100) Ibid., p. 166.

(101) Par exemple ibid., p. 23, avec une citation des Proverbes (Pr 14, 28). Voir tout le chapitre III intitulé « En favor de la soberanía del pueblo el c. 14 de los Proverbios ». 
que des usurpateurs, des magiciens, des fourriers de l'idolâtrie. Roscio sacralisait le peuple comme image du corps du Christ d'où découlait toute autorité, tout pouvoir, toute légitimité. La volonté générale était ainsi redéfinie comme «le résumé des forces spirituelles et corporelles du Peuple $»^{102}$.

On ignore l'impact du livre en Terre-Ferme. Il circula mais sa forme était trop complexe pour qu'il puisse convaincre au-delà d'un petit cercle lettré. Le Triomphe avait le mérite de prouver la légitimité catholique, avec des touches protestantes, de la république et c'était là l'essentiel. Roscio retrouva le Venezuela en 1818 pour présider un nouveau congrès constituant, réuni à Angostura ${ }^{103}$. En 1819, il devint vice-président de la République de Colombie pour le département du Venezuela. Dans le même temps, il fut, avec Francisco Antonio Zea, l'un des principaux rédacteurs du journal officiel des patriotes, le Correo del Orinoco. Il put, à partir de cette tribune, diffuser ses idées. L'un de ses derniers textes fut consacré au rétablissement de la constitution espagnole de Cadix après 1820. L'article, publié dans le Correo del Orinoco, s'adressait implicitement aux libres de couleur. De façon pédagogique, Roscio leur expliquait que la loi espagnole était mauvaise parce qu'elle continuait à discriminer les Afrodescendants. Il ne fallait pas qu'ils fussent trompés une « seconde fois » après le premier épisode libéral : la république de Colombie était beaucoup plus généreuse avec eux que les Cortes de Madrid. La peur d'un soulèvement des « zambos, mulâtres, noirs, coyotes, etc. » ${ }^{104}$ représentait toujours l'un des points focaux de la pensée de l'avocat métis. Preuve en est que l'indépendance avait érigé les populations métisses en acteurs centraux du processus révolutionnaire et de la vie politique. Élu au congrès constituant de Cúcuta qui devait créer les institutions définitives de la Colombie bolivarienne, Roscio mourut prématurément le 31 mars 1821, à l'âge de 57 ans, alors que la convention constituante n'avait pas commencé à siéger.

L'itinéraire atlantique de Roscio au cours des révolutions d'indépendance hispaniques offre l'occasion d'explorer certaines facettes méconnues

(102) Ibid., p. 29

(103) Voir, pour ces détails, le récit de DuCOUdRAY-Holstern, op. cit., p. 139-142.

(104) Juan Germán Roscio, «Artículo comunicado », Correo del Orinoco, n 72, 22 juillet 
du premier républicanisme latino-américain ${ }^{105}$. Depuis le $\mathrm{XIX}^{\mathrm{e}}$ siècle, l'historiographie libérale a rapporté ce trait aux influences américaines et françaises, plus fortes ici qu'ailleurs. Si les références aux précédentes révolutions atlantiques furent en effet massives ${ }^{106}$, le basculement vers le républicanisme s'explique aussi par les particularités sociopolitiques de la Terre-Ferme. Cette forme de régime était seule capable, aux yeux de ses défenseurs, d'y constituer, au sens fort du terme, les corps politiques libres de l'Amérique espagnole. Les républiques formaient des communautés susceptibles d'être articulées à différentes échelles par des liens fédératifs, depuis les simples villages jusqu'au continent dans son entier comme le voulut Simón Bolívar au congrès de Panamá. Elles étaient également une forme de gouvernement libre, fondée sur l'équilibre des pouvoirs et l'égalité des citoyens. Ce dernier caractère, aveugle aux lignes de couleur, devait faciliter la transformation de sociétés racialisées en un corps de nation sans basculer dans la « guerre des races ». Toutes ces promesses ne furent pas tenues mais la Terre-Ferme fut le premier espace qui accorda définitivement le droit de citoyenneté aux libres de couleur ${ }^{107}$. Juan Germán Roscio contribua ainsi à l'une des mutations les plus profondes du monde hispanique et atlantique dans son ensemble.

Clément THIBAUD

CRHIA-Nantes

Faculté des lettres et Sciences humaines, BP 81227 , 44312 Nantes cedex 3 Clement.thibaud@univ-Nantes.fr

(105) Les aspects religieux ou littéraires de sa pensée ont été bien étudiés, moins son apport, décisif, au premier républicanisme hispanique. Voir par exemple Francisco José VIRTUoso, La crisis de la catolicidad en los inicios republicanos de Venezuela (1810-1813), Caracas, Universidad Católica Andrés Bello, 2001; Luz Ainai Morales Pino, Juan Germán Roscio y la subversión de la palabra, Caracas, Universidad Católica Andrés Bello, 2008. Il faut mettre à part les travaux de Nydia RuIz, Las confesiones..., op. cit. et de François-Xavier Guerra, « Políticas... », loc. cit. qui proposent des pistes fondamentales pour comprendre la pensée politique de Roscio.

(106) Pierre SERna(dir.), Républiquessoeurs, le Directoire etla Révolutionatlantique, Rennes, Presses Universitaires de Rennes, 2009.

(107) Avec Haïti. Mais contrairement à la république noire, l'esclavage ne fut pas aboli au Venezuela pendant l'indépendance. 